\title{
Determination of amount of irrigation and nitrogen for comprehensive growth of greenhouse cucumber based on multi-level fuzzy evaluation
}

\author{
Zhihao He ${ }^{1,2}$, Tingting Hong ${ }^{1,2}$, Zelin Cai ${ }^{1,2}$, Zhi Yang ${ }^{1,2}$, Manning $\mathrm{Li}^{1,2}$, Zhi Zhang ${ }^{1,2^{*}}$ \\ (1. College of Horticulture, Northwest A\&F University, Yangling 712100, Shaanxi, China; \\ 2. Key Laboratory of Protected Horticultural Engineering in Northwest, Ministry of Agriculture, Yangling 712100, Shaanxi, China)
}

\begin{abstract}
In the northwestern part of China, rational and efficient management of irrigation and nitrogen significantly affects the intensive production of greenhouse cucumbers (Cucumis sativus L). To evaluate the effects of different combinations of water use and nitrogen $(\mathrm{N})$ on yield, quality, and profitability of the greenhouse cucumbers that planted in 2018 Spring, nine combined treatments were applied. Results indicated the optimal irrigation and nitrogen demands for yield, quality and other indicators were different. The irrigation amount significantly affected the yield, and the yield gradually increased with increasing in irrigation. Single fruit weight (SFW) was significantly affected by the amount of irrigation, nitrogen and their interactions, and the higher amounts of $\mathrm{N}$ and irrigation were beneficial to the increase of SFW. The partial factor productivity of the applied $\mathrm{N}\left(\mathrm{PFP}_{\mathrm{N}}\right)$ gradually increased with the nitrogen amount decline. Irrigation water use efficiency (IWUE) was closely related to the amount of irrigation. The higher irrigation amount would lead to the lower IWUE. When the amounts of irrigation and nitrogen were at an intermediate level, the content of vitamin $\mathrm{C}(\mathrm{VC})$ reached the maximum. As the amount of nitrogen was increased or irrigation was decreased, the Nitrate content (NC) would increase. Free amino acid (FAA) and NC followed a similar variation. When the amounts of irrigation and nitrogen both were at medium levels, the total soluble sugar concentration (TSSC) reached the highest. The multi-level fuzzy evaluation method was used to evaluate different indicators of cucumber. The weights of indicators in the first and second layer were determined by analytic hierarchy process (AHP) and entropy weight method, respectively. Then the fuzzy algorithm was used to comprehensively evaluate all the treatments. The evaluation results show that T4 (irrigation, $1957.6 \mathrm{~m}^{3} / \mathrm{hm}^{2} ; \mathrm{N}, 210 \mathrm{~kg} / \mathrm{hm}^{2}$ ) is the best strategy for greenhouse cucumber irrigation and nitrogen management in the northwestern part of China.
\end{abstract}

Keywords: Cucumis sativus L, water and nitrogen coupling, yield, PFPN, IWUE, quality, multi-level fuzzy evaluation DOI: $10.25165 /$ j.ijabe.20211402.5785

Citation: He Z H, Hong T T, Cai Z L, Yang Z, Li M N, Zhang Z. Determination of amount of irrigation and nitrogen for comprehensive growth of greenhouse cucumber based on multi-level fuzzy evaluation. Int J Agric \& Biol Eng, 2021; 14(2): $35-42$.

\section{Introduction}

Cucumber is a horticultural crop widely grown worldwide because of its distinct taste and high yield. Irrigation and nutrient supplementation are particularly important in cucumber growth and development. Thus, efficient irrigation and fertilization measures are necessary ${ }^{[1,2]}$. Water shortage and less arable soil are common in the northwestern part of $\mathrm{China}^{[3]}$. Water wastage and destruction of the soil structure have led to the rapid development of water-saving irrigation and precision fertilization ${ }^{[4]}$. In 2015, the Ministry of Agriculture of China, emphasized the need for economical and efficient water and fertilizer management in agricultural production to ensure crop yield and quality ${ }^{[5]}$.

\section{Received date: 2020-03-21 Accepted date: 2020-08-17}

Biographies: Zhihao He, PhD, research interests: crop models and algorithms, Email: hezhihaode@163.com; Tingting Hong, Master, research interests: Efficient utilization of water and fertilizer, Email: ruopuxiongmao@163.com; Zelin Cai, Master, research interests: Efficient utilization of water and fertilizer, Email: alexc538@126.com; Zhi Yang, Master, research interests: Efficient utilization of water and fertilizer, Email: yz15511021996@163.com; Manning Li, Master, research interests: Efficient utilization of water and fertilizer, Email: limanning1996@163.com.

*Corresponding author: Zhi Zhang, $\mathrm{PhD}$, Associate professor, research interests: Intelligent regulation in greenhouse environment and water- fertilizer, College of Horticulture, Northwest A\&F University, Yangling 712100, Shaanxi, China. Tel: +86-18702945429, Email: zhangzhione@126.com.
Crops are highly sensitive to water supply, and the amount of water directly affects the metabolism of crops $^{[6,7]}$. Nitrogen is one of the main nutrients absorbed by crops. In a greenhouse, nitrogen is mainly implemented by fertilizers. If not used properly, nitrogen can cause a decline in crop yield and quality ${ }^{[8]}$. Deficit irrigation leads to a reduction in final yield and single fruit weight (SFW). However, moderate deficit irrigation can ensure the quality of vitamin $\mathrm{C}(\mathrm{VC})$ and total soluble sugar concentration (TSSC) of the fruit ${ }^{[9,10]}$. Nitrogen can increase crop yield, but its excessive use can significantly affect the nitrate content (NC) and free amino acid (FAA) in fruits ${ }^{[11,12]}$. In the northwestern part of China, severe water shortage occurs; thus, reasonable irrigation methods need to be developed. Submembrane drip irrigation is a reliable water-saving technique in which moisture is accurately injected into the roots of crops when the spacing between crops and the drip zone is consistent. The close association between fertilization and irrigation allows the use of drip irrigation for fertilization, which not only improves IWUE but also reduces nitrogen leaching and improves the partial factor productivity of applied $\mathrm{N}\left(\mathrm{PFP}_{\mathrm{N}}\right)^{[13]}$.

For irrigation management and nitrogen fertilization of cucumber in a greenhouse, varying the amounts of irrigation and nitrogen can significantly affect yield, quality, and profitability of cucumber. Moreover, the interaction between irrigation and nitrogen exerts different effects on the various indicators of cucumber. Numerous studies have been conducted on the 
irrigation and nitrogen management in cucumber growth, but for different single indicators, the optimal solution is different ${ }^{[14,15]}$. Various methods, such as the use of questionnaires, analytic hierarchy process (AHP), grey relational analysis (GRA), and principal components analysis (PCA), have been widely used in the evaluation of crop growth and development ${ }^{[16,17]}$. However, some of these approaches are influenced by human factors, and some are directly evaluated based on data, resulting in uncertainty in the final outcome. Multi-level fuzzy comprehensive evaluation can carry out collaborative evaluation of multiple indicators. This method combines qualitative and quantitative data, obtaining more accurate final evaluation results through fuzzy evaluation of indicators at all levels ${ }^{[18]}$.

The current study mainly aims (1) to explore the individual and combined effects of irrigation and nitrogen on different indicators of cucumber; (2) to establish the comprehensive evaluation of cucumber growth by multi-level fuzzy method and analyze the response to different water-nitrogen combinations; and (3) to determine the optimal irrigation and nitrogen management for the comprehensive growth of cucumber in northwest China.

\section{Materials and method}

\subsection{Experimental site and cropping details}

The experiment was conducted in a greenhouse in the Northwest A\&F University campus (latitude $34^{\circ} 16^{\prime} \mathrm{N}$, longitude $108^{\circ} 02^{\prime} \mathrm{E}$, altitude $450 \mathrm{~m}$ ) in China. The test area is located in a warm temperate semi humid climate zone with an annual average temperature of $13^{\circ} \mathrm{C}$, an annual average evaporation of $1500 \mathrm{~mm}$, and an average annual precipitation of $645 \mathrm{~mm}$. Rainfall received in this area is concentrated between July and September. The greenhouse was made of a steel frame $100 \mathrm{~m}$ long and $17 \mathrm{~m}$ wide, with a double-layer polyethylene sheet on the surface. The orientation is east-west, with crop rows oriented in the north-south direction. To eliminate the test error caused by the greenhouse microclimate, the test plot was only set in the south span, and 4 rows of protection were planted near the exit and the innermost side. The basic physical and chemical properties of the test soil were as follows: ammonium nitrate nitrogen, $27.48 \mathrm{mg} / \mathrm{kg}$; available phosphorus, $23.64 \mathrm{mg} / \mathrm{kg}$; available potassium, $152.14 \mathrm{mg} / \mathrm{kg}$; electrical conductivity (EC), $0.34 \mathrm{mS} / \mathrm{cm}$; $\mathrm{pH} 7.32$; soil bulk density, $1.34 \mathrm{~g} / \mathrm{cm}^{3}$; organic matter mass fraction, $5.89 \mathrm{~g} / \mathrm{kg}$; and field capacity of a $0-60 \mathrm{~cm}$ soil layer, $24.3 \%$.

Cucumber seedlings (Cucumis sativus L. cv. Bonai 14-3) were transplanted to the field on March 15, 2018 and then uprooted on July 20, 2018. To reduce evapotranspiration and achieve irrigation retention, a drip tape (spacing $=0.5 \mathrm{~m}$; flow rate $=1.5 \mathrm{LPH}$ ) was used for drip irrigation under the mulch plastic film (color, black; thickness, $0.006 \mathrm{~mm}$ ). Thus, the plant spacing of the cucumbers was consistent with the drip tape. Each cucumber plant was fixed in a vertical direction with a nylon rope. Field management was coordinated and uniform in accordance with the common methods applied by the local farmers.

\subsection{Experimental design}

The experiments were conducted using a completely randomized block design in three replicates. Nine combined treatments were implemented, including three different irrigation levels and three different nitrogen $(\mathrm{N})$ levels (Table 1). Each treated plot $(9 \mathrm{~m}$ long and $1.2 \mathrm{~m}$ wide) was planted with 32 cucumber plants. A base fertilizer was first applied to the planting ridges of each treated plot $\left(\mathrm{P}_{2} \mathrm{O}_{5}, 240 \mathrm{~kg} / \mathrm{hm}^{2} ; \mathrm{K}_{2} \mathrm{O}, 320 \mathrm{~kg} / \mathrm{hm}^{2} ; \mathrm{N}\right.$, $60 \mathrm{~kg} / \mathrm{hm}^{2}$ ) before the plants were transplanted. All plots were then irrigated to field capacity. When the cucumber reached the flowering stage, different amounts of irrigation and $\mathrm{N}$ were applied to all plots (Table 1). The $\mathrm{N}$ fertilizer (urea) that needed to be applied was put into the fertilizing bucket and dissolved with water, then the mixed solution was pumped out to the drip irrigation belt by the fertilizer applicator, and water and fertilizer were applied to the roots of cucumber. Fertilizers were applied using high-frequency drip fertigation weekly for a total of 10 times.

Table 1 Amounts of irrigation and $\mathbf{N}$ fertilizer

\begin{tabular}{ccccc}
\hline Treatment & $\begin{array}{c}\text { Irrigation } \\
\text { level }\end{array}$ & $\begin{array}{c}\text { Amount of } \\
\text { irrigation } / \mathrm{m}^{3} \cdot \mathrm{hm}^{-2}\end{array}$ & $\begin{array}{c}\text { Nitrogen } \\
\text { level }\end{array}$ & $\begin{array}{c}\text { Amount of Nitrogen } \\
/ \mathrm{kg} \cdot \mathrm{hm}^{-2}\end{array}$ \\
\hline $\mathrm{T} 1$ & & & $\mathrm{~N} 1$ & $60+150$ \\
$\mathrm{~T} 2$ & $\mathrm{I} 1\left(\theta_{f}+0.5 \Delta f\right)$ & 1464.1 & $\mathrm{~N} 2$ & $60+255$ \\
$\mathrm{~T} 3$ & & & $\mathrm{~N} 3$ & $60+360$ \\
\hline $\mathrm{T} 4$ & & \multirow{2}{*}{1957.6} & $\mathrm{~N} 1$ & $60+150$ \\
$\mathrm{~T} 5$ & $\mathrm{I} 2\left(\theta_{f}+0.75 \Delta f\right)$ & & $\mathrm{N} 2$ & $60+255$ \\
$\mathrm{~T} 6$ & & & $\mathrm{~N} 3$ & $60+360$ \\
\hline $\mathrm{T} 7$ & & 2869.1 & $\mathrm{~N} 2$ & $60+150$ \\
$\mathrm{~T} 8$ & $\mathrm{I} 3\left(\theta_{f}+\Delta f\right)$ & & $\mathrm{N} 3$ & $60+255$ \\
$\mathrm{~T} 9$ & & & $60+360$ \\
\hline
\end{tabular}

Notes: $\theta_{f}$ is the amount of water required at field capacity for seedling recovery after transplantation; $\Delta f$ is the amount of water required to irrigate a $0-60 \mathrm{~cm}$ soil layer from $50 \%$ to $100 \%$ field capacity. The amount of nitrogen is composed of the amount of base nitrogen fertilizer + the amount of nitrogen applied later.

\subsection{Measurements}

The meteorological data in the greenhouse were recorded by a small weather station (HOBO Event Data Logger, Onset Computer Corp., USA), which automatically logs the temperature $\left({ }^{\circ} \mathrm{C}\right)$, relative humidity (\%), and luminous intensity (Lux) simultaneously. Water content in the soil was recorded using a soil moisture meter (TDR-300, Spectrum Technologies, Inc., USA), which logs data on the relative water content $(\%)$ in the soil.

The SFW was measured, and the number of fruits was recorded during the ripening period of the cucumber. The degree of fruit maturity had to be consistent, and the yield was recorded at intervals of 3-4 $\mathrm{d}$ in general. Ten plants were labeled in each plot to determine the yield.

IWUE is calculated as follows ${ }^{[19]}$ :

$$
\text { IWUE }=\frac{Y}{I}
$$

where, IWUE is the irrigation water use efficiency, $\mathrm{kg} / \mathrm{m}^{3} ; Y$ is the cucumber yield, $\mathrm{t} / \mathrm{hm}^{2}$; and $I$ is the drip irrigation water consumption, $\mathrm{m}^{3} / \mathrm{hm}^{2}$.

$\mathrm{PFP}_{\mathrm{N}}$ is calculated as follows ${ }^{[20]}$ :

$$
\mathrm{PFP}_{\mathrm{N}}=\frac{Y}{F_{N} \times 1000}
$$

where, $\mathrm{PFP}_{\mathrm{N}}$ is the partial factor productivity of applied $\mathrm{N}, \mathrm{kg} / \mathrm{kg}$; and $F_{N}$ is the amount of total $\mathrm{N}$ application, $\mathrm{kg} / \mathrm{hm}^{2}$ ).

When the cucumber reached the middle fruiting period (June 15), six cucumbers were picked from different plants, and the middle part of the fruit was removed to evaluate the quality of the cucumber, including VC, NC, TSSC, and FAA. VC was determined by molybdenum blue colorimetry ${ }^{[21]}$; $\mathrm{NC}$ was measured by ultraviolet spectrophotometry ${ }^{[22]}$; TSSC was quantified by anthrone colorimetry ${ }^{[23]}$; and FAA was measured by ninhydrin solution colorimetry ${ }^{[24]}$.

\subsection{Multi-level fuzzy comprehensive evaluation}

2.4.1 Constructing fuzzy evaluation factor set and its sub-factor set

(1) All indicators of cucumber were categorized into yield index, profit index, and quality index. 


$$
U_{i}=\left\{u_{1}, u_{2}, u_{3}\right\}
$$

(2) All secondary indicators were classified and defined as subfactors. Yield and SFW were classified as yield indices; $\mathrm{PFP}_{\mathrm{N}}$ and IWUE were classified as profit indices; and VC, NC, TSSC, and FAA were classified as quality indices.

$$
u_{i j} \rightarrow\left(\begin{array}{l}
u_{1}=\left\{u_{11}, u_{12}\right\} \\
u_{2}=\left\{u_{21}, u_{22}\right\} \\
u_{3}=\left\{u_{31}, u_{32}, u_{33}, u_{34}\right\}
\end{array}\right)
$$

\subsubsection{Constructing evaluation set}

Each factor and its subfactors had a set of evaluation values corresponding to the subordinates. The test consisted of 9 treatments, generating 9 evaluation values.

$$
V_{i}=\left\{V_{1}, V_{2}, \ldots, V_{9}\right\}
$$

$$
v_{i j}=\left\{v_{1}, v_{2}, \ldots, v_{9}\right\}
$$

\subsubsection{Multi-level fuzzy comprehensive evaluation}

(1) Determination of factor weights by analytic hierarchy process (AHP)

AHP is currently the most widely known evaluation method ${ }^{[25]}$ AHP is based on the results of the questionnaire to establish a judgment matrix, which decomposes the total decision into a target layer, a factor layer, and a subfactor layer (Figure 1). By analyzing the relationship between the indicators and establishing a comparison matrix, the complex problem is decomposed into several criteria and indicators. Each indicator is then compared and calculated to determine the individual weight of each indicator in the hierarchical model. Specific calculation methods are provided in most of the available literatures ${ }^{[26,27]}$.

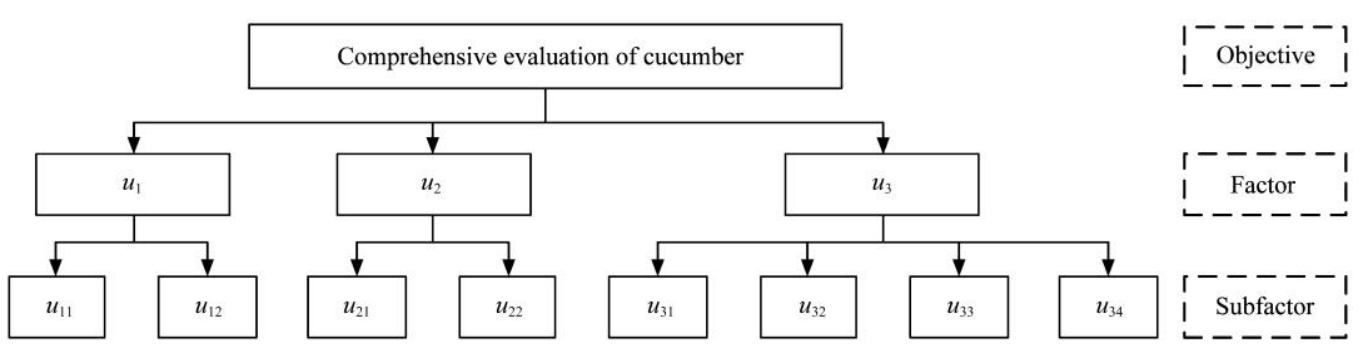

Note: Terms $u_{1}-u_{3}$ denote yield index, profit index, and quality index, respectively. $\quad u_{11}$ is the yield of cucumber, $u_{12}$ is the SFW; $u_{21}$ is PFP,$u_{22}$ is IWUE; $u_{31}$ denotes VC, $u_{32}$ is NC, while $u_{33}$ and $u_{34}$ denote TSSC and FAA, respectively.

Figure 1 Cucumber comprehensive evaluation hierarchical model

(2) Determination of subfactor weights by the entropy method

The entropy method is the main approach used to determine the objective weight of an indicator. They can effectively reflect the information implied by the data and exhibit strong operability $^{[28]}$. The specific calculation process of the entropy method can refer to Reference ${ }^{[29-31]}$.

(3) Calculation of multi-level fuzzy evaluation values

Single-level fuzzy evaluation of factor sets

$$
\begin{aligned}
& b_{i z}=w_{i j} \cdot r_{j z} \\
& =\left[\begin{array}{llll}
w_{11} & w_{12} & \cdots & w_{1 m} \\
w_{21} & w_{22} & \cdots & w_{2 m} \\
w_{31} & w_{32} & \cdots & w_{3 m}
\end{array}\right] \cdot\left[\begin{array}{cccc}
r_{11} & r_{12} & \cdots & r_{1 n} \\
r_{21} & r_{22} & \cdots & r_{2 n} \\
\vdots & \vdots & & \vdots \\
r_{m 1} & r_{m 2} & \cdots & r_{m n}
\end{array}\right] \\
& =\left[\begin{array}{llll}
b_{11} & b_{12} & \cdots & b_{1 n} \\
b_{21} & b_{22} & \cdots & b_{2 n} \\
b_{31} & b_{32} & \cdots & b_{3 n}
\end{array}\right]
\end{aligned}
$$

where, $b_{\mathrm{iz}}$ is the fuzzy evaluation index of the $i$ th factor set.

Quadratic fuzzy evaluation of the subfactor set:

$$
\begin{aligned}
& B_{z}=a_{i} \times b_{i z} \\
& =\left[a_{1}, a_{2}, a_{3}\right] \cdot\left[\begin{array}{l}
b_{11}, b_{12}, \cdots, b_{1 n} \\
b_{21}, b_{22}, \cdots, b_{2 n} \\
b_{31}, b_{32}, \cdots, b_{3 n}
\end{array}\right] \\
& =\left[\begin{array}{lll}
B_{1}, B_{2}, \cdots, B_{n}
\end{array}\right] \\
& =\left[\begin{array}{llll}
b_{11} & b_{12} & \cdots & b_{1 n} \\
b_{21} & b_{22} & \cdots & b_{2 n} \\
b_{31} & b_{32} & \cdots & b_{3 n}
\end{array}\right]
\end{aligned}
$$

where, $B_{z}$ refers to the comprehensive fuzzy evaluation index of the $z^{\text {th }}$ treatment.

\subsection{Data analysis}

MATLAB (MathWorks, MA, USA) was used to calculate multi-level fuzzy comprehensive evaluation. All statistical analysis were conducted using SPSS (IBM, Chicago, USA). The Duncan test was used to analyze multiple comparisons between different treatments and the interaction of irrigation and of $\mathrm{N}$ fertilizer at a significance level of $5 \%$.

\section{Results}

\subsection{Effects of irrigation and nitrogen on yield and single fruit weight}

Yields are only significantly affected by irrigation, ranked as follows: I3>I2>I1. The yield of I3 was only $7.2 \%$ higher than that of I2, but these two values were both over $25 \%$ higher than yield of I1 (Table 2). For the different treatments, T9 achieved the highest treatment yield, which was significantly higher than that of T3 (the lowest) by $42.9 \%$ (Figure 2). The SFW was significantly affected by irrigation, nitrogen, and their interaction. When I3 was applied, the SFW achieved $6.6 \%$ and $26.4 \%$ higher than that achieved by $\mathrm{I} 2$ and I1, respectively; from the level of nitrogen application, N2 achieved 9.0\% higher than when N1 was implemented (Table 2). The largest SFW was processed at T9, which was 39.2\% higher that of T3, the lowest. As shown in Figure 2, as the amounts of irrigation and $\mathrm{N}$ increase, yield and SFW tend to increase as well.

\subsection{Effects of irrigation and nitrogen on PFP $_{\mathrm{N}}$ and IWUE}

Irrigation and nitrogen were significantly affected $\mathrm{PFP}_{\mathrm{N}}$, but their interaction was not significant. The impact of irrigation on $\mathrm{PFP}_{\mathrm{N}}$, in the descending order is described as $\mathrm{I} 3>\mathrm{I} 2>\mathrm{I} 1$. The difference in $\mathrm{PFP}_{\mathrm{N}}$ between different amounts of nitrogen applied was significant, the rank was $\mathrm{N} 1>\mathrm{N} 2>\mathrm{N} 3$ (Table 2). At the same nitrogen application level, it was shown that $\mathrm{PFP}_{\mathrm{N}}$ increased with an increase in irrigation (Figure 3). Among all treatments, T7 and T3 exhibited the highest and lowest $\mathrm{PFP}_{\mathrm{N}}$, respectively. Meanwhile, IWUE was significantly affected only by irrigation but nitrogen and their interactions. Similarly, differences in irrigation level led to significant differences in IWUE (Table 2). With the irrigation amount remaining the same, the nitrogen amount played limited effect on IWUE, T1 was only 5.5\% higher than T3, that is 
the biggest difference in all treatment (Figure 3). Among all treatments, T1 clearly showed the best results, whereas T7 achieved the poorest results.

3.3 Effects of irrigation and nitrogen on the quality of cucumber fruit

$\mathrm{VC}$ in cucumber fruit was significantly affected by irrigation and the interaction between the amounts of irrigation and $\mathrm{N}$ fertilizer. The maximum $\mathrm{VC}$ was achieved when the irrigation level applied was I2 (Table 2). Under the interaction of irrigation and nitrogen, T5 showed the best value in VC, which was $45.5 \%$ higher than the lowest. When irrigation amount increased, VC increased first and then decreased. By contrast, with an increase in nitrogen amount, $\mathrm{VC}$ appeared increased and then decreased (Figure 4). With regard to NC, NC was significantly affected by irrigation, nitrogen, and their interaction. The different irrigation levels, ranked in descending order by the extent of their effect on $\mathrm{NC}$, are I1 $>\mathrm{I} 2>\mathrm{I} 3$; according to the different nitrogen application rates, ranked in descending order by the extent of their effect on $\mathrm{NC}$, are $\mathrm{N} 3>\mathrm{N} 2>\mathrm{N} 1$ (Table 2). But there is not much difference between $\mathrm{N} 1$ and $\mathrm{N} 2$ on NC. Among all treatments, T3 achieved the highest NC, which was significantly higher than that of T7, which exhibited the lowest NC, by $26.4 \%$. As irrigation amount increased, the $\mathrm{NC}$ was gradually decreased, but there is no significant difference between I 2 and I 3 although the NC of I 2 was slightly higher than that of $\mathrm{I} 3$. The nitrogen amount has an opposite effect on NC, which achieved by $\mathrm{N} 2$ was higher than that of N1 and no significant difference, too (Table 2). TSSC was significantly affected by irrigation and nitrogen but not by their interaction. The different irrigation levels, ranked in descending order by the extent of their effect on TSSC, are I2>I1 $>\mathrm{I} 3$. The different amounts of $\mathrm{N}$, ranked in descending order by the extent of their effect on TSSC, are N2>N3>N1 (Table 2). Therefore, moderately reducing nitrogen amount can increase the content of TSSC. Among all treatments of TSSC, T5 exhibited the highest processing and was significantly higher than $\mathrm{T} 7$, which exhibited the lowest processing, by $49.5 \%$ (Figure 4). FAA was significantly affected by irrigation, nitrogen, and their interaction. The different irrigation levels are I1 $>\mathrm{I} 2>\mathrm{I} 3$, ranked in descending order by the extent of their effect on FAA; meanwhile, the nitrogen levels are $\mathrm{N} 3>\mathrm{N} 2>\mathrm{N} 1$, ranked in descending order by the extent of their effect on FAA (Table 2). T3 exerted the greatest effect on FAA content, and this effect was significantly higher than that of T7, which exerted the lowest influence on FAA, by $45.8 \%$. The FAA responded to interactions similarly to $\mathrm{NC}$, but the FAA achieved by $\mathrm{I} 2$ was significantly higher than that of I3. With the irrigation amount decreased and nitrogen applied increased, the FAA showed a rising trend (Table 2 and Figure 3).

\subsection{Multi-level fuzzy comprehensive evaluation of cucumber}

In the multi-level fuzzy comprehensive evaluation analysis of cucumber, the weight of factor $\left(a_{i}\right)$ in the first layer and the weight of subfactor $\left(w_{i j}\right)$ in the second layer were calculated by AHP and the entropy method, respectively (Tables 3 and 4). Seen from the category's factors, the yield index had the greatest impact on the comprehensive growth of cucumber (0.421), followed by the quality index (0.354), and the profit index had the lowest impact on it (0.255). The weight ranking of the sub-factors of each category were described as Yield > SFW; $\mathrm{PFP}_{\mathrm{N}}>$ IWUE; TSSC > VC > FAA $>$ NC. By using multi-level fuzzy comprehensive evaluation, the weights of factors and subfactors were merged. The fuzzy evaluation values of all treatments were shown in Figure 5. The higher fuzzy evaluation value of the treatment would be more conducive to the comprehensive growth of cucumber. The final result indicated that $\mathrm{T} 4$ was the best, followed by $\mathrm{T} 5 . \mathrm{T} 3$ was the most unfavorable for the comprehensive growth of cucumber.

Table 2 Mean values of yield, profit, and fruit quality of cucumber under the influence of different amounts of irrigation, Nitrogen and their interaction based on Two-way ANOVA

\begin{tabular}{|c|c|c|c|c|c|c|c|c|}
\hline Factors & $\mathrm{Y} / \mathrm{t} \cdot \mathrm{hm}^{-2}$ & $\mathrm{SFW} / \mathrm{g}$ & $\mathrm{PFP}_{\mathrm{N}} / \mathrm{kg} \cdot \mathrm{kg} \mathrm{N}^{-1}$ & IWUE $/ \mathrm{kg} \cdot \mathrm{m}^{-3}$ & $\mathrm{VC} / \mathrm{mg} \cdot 100 \mathrm{~g}^{-1}$ & $\mathrm{NC} / \mathrm{mg} \cdot \mathrm{kg}^{-1}$ & $\mathrm{TSSC} / \%$ & FAA $/ \mathrm{mg} \cdot 100 \mathrm{~g}^{-1}$ \\
\hline I1 & $69.21 \mathrm{c}$ & $204.08 b$ & $239.40 \mathrm{~b}$ & $47.27 \mathrm{a}$ & $8.14 b$ & $231.28 \mathrm{a}$ & $2.22 b$ & $41.54 \mathrm{a}$ \\
\hline I 2 & $86.62 b$ & $241.99 \mathrm{ab}$ & $296.10 \mathrm{ab}$ & $47.45 \mathrm{a}$ & $8.78 \mathrm{a}$ & $202.48 b$ & $2.81 \mathrm{a}$ & $36.93 b$ \\
\hline $\mathrm{I} 3$ & $92.89 \mathrm{a}$ & $258.02 \mathrm{a}$ & $317.55 \mathrm{a}$ & $30.19 b$ & $6.66 \mathrm{c}$ & $201.94 b$ & $2.07 \mathrm{c}$ & $34.03 \mathrm{c}$ \\
\hline N1 & 81.83 & $227.28 b$ & $389.67 \mathrm{a}$ & 41.31 & 7.85 & $204.69 b$ & $2.29 b$ & $35.35 \mathrm{~b}$ \\
\hline $\mathrm{N} 2$ & 82.47 & $247.72 \mathrm{a}$ & $264.15 b$ & 42.39 & 8.04 & $208.06 b$ & $2.46 a$ & $36.74 b$ \\
\hline I & $* * *$ & $* *$ & $* *$ & $* *$ & $* *$ & * & $* * *$ & $* *$ \\
\hline $\mathrm{N}$ & ns & $*$ & $* * *$ & $\mathrm{~ns}$ & $\mathrm{~ns}$ & $* *$ & $*$ & $*$ \\
\hline $\mathrm{I} \times \mathrm{N}$ & $\mathrm{ns}$ & $* *$ & ns & $\mathrm{ns}$ & $*$ & $*$ & $\mathrm{~ns}$ & $*$ \\
\hline
\end{tabular}

Note: $*=p<0.05, * *=p<0.01, * * *=p<0.001, \mathrm{~ns}=$ no significance.

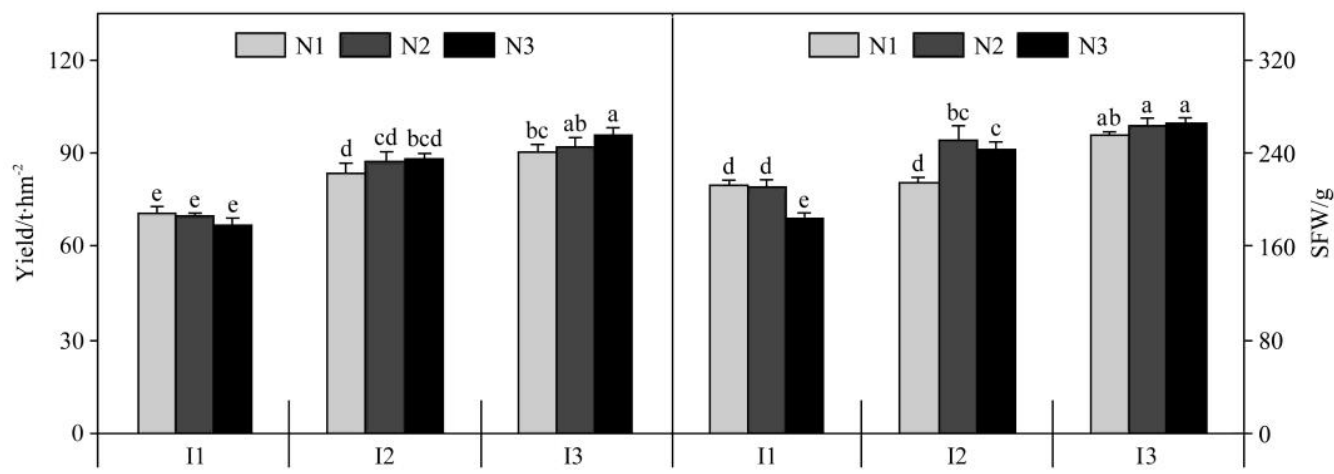

Note: Error bars indicate standard error of the mean $(n=3)$. The different letters of each data represent the differences between the treatments based on Duncan's analysis at $p<0.05$. Statistical comparisons between different factors are listed in Table 2 .

Figure 2 Yield (Y) and single fruit weight (SFW) influenced by irrigation (I1, I2 and I3) and nitrogen (N1, N2 and N3) 


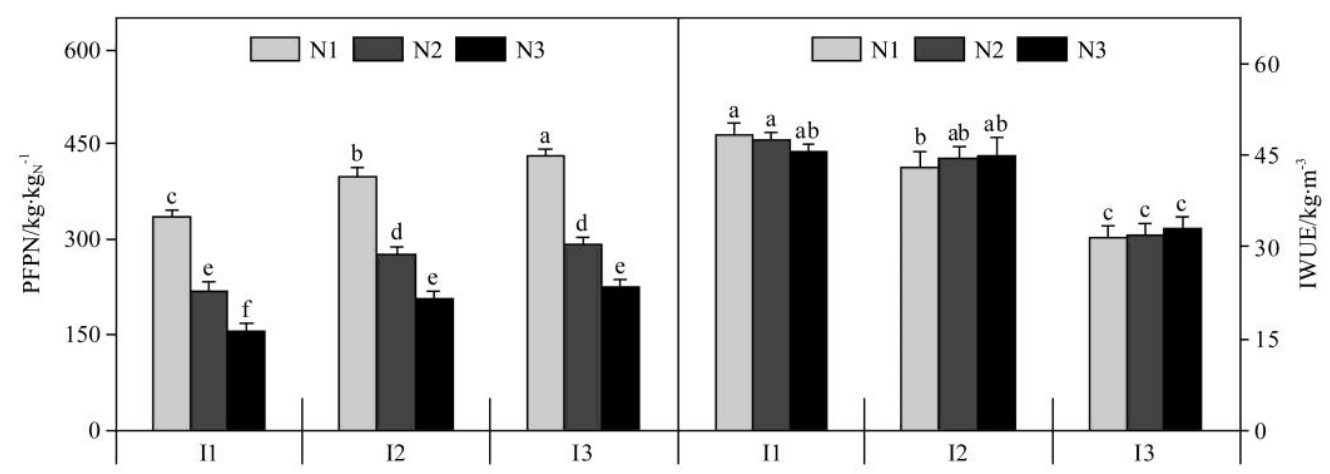

Note: Error bars indicate standard error of the mean $(n=3)$. The different letters of each data represent the differences between the treatments based on Duncan's analysis at $p<0.05$. Statistical comparisons between different factors are listed in Table 2 .

Figure $3 \quad \mathrm{PFP}_{\mathrm{N}}$ and IWUE influenced by the irrigation and nitrogen

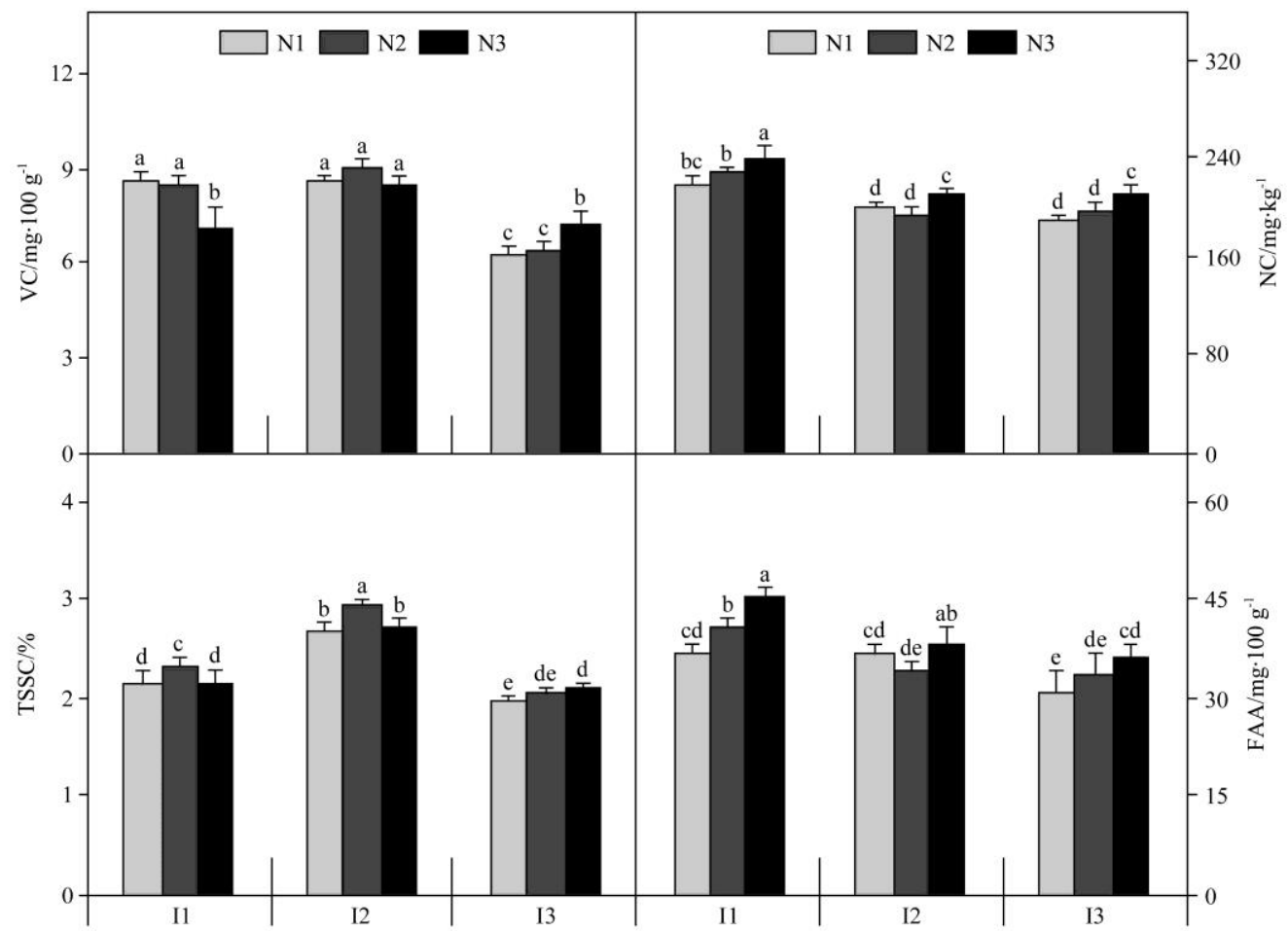

Note: Error bars indicate standard error of the mean $(n=3)$. The different letters of each data represent the differences between the treatments based on Duncan's analysis at $p<0.05$. Statistical comparisons between different factors are listed in Table 2.

Figure 4 VC, NC, TSSC, FAA influenced by the irrigation and nitrogen

Table 3 Subjective weights of factors determined using AHP

\begin{tabular}{|c|c|c|c|c|c|c|c|c|}
\hline & \multicolumn{5}{|c|}{ Contrast matrix } & Local weight & Final weight & Consistency test \\
\hline \multirow{4}{*}{$U \sim u_{\mathrm{i}}$} & Index & $u_{1}$ & & $u_{2}$ & $u_{3}$ & $l_{i}$ & $a_{i}$ & \multirow{4}{*}{$\begin{array}{c}\mathrm{CR}=0.051 \\
\lambda_{\max }=3.054\end{array}$} \\
\hline & $u_{1}$ & 1.00 & & 1.50 & 1.50 & 0.421 & 0.421 & \\
\hline & $u_{2}$ & 0.67 & & 1.00 & 0.50 & 0.225 & 0.225 & \\
\hline & $u_{3}$ & 0.67 & & 2.00 & 1.00 & 0.354 & 0.354 & \\
\hline \multirow{2}{*}{$u_{1} \sim u_{1 \mathrm{j}}$} & Index & \multicolumn{2}{|c|}{$u_{11}$} & \multicolumn{2}{|c|}{$u_{12}$} & $l_{1 j}$ & $a_{1 j}$ & \multirow{2}{*}{$\begin{array}{c}\mathrm{CR}=0 \\
\lambda_{\max }=2.000\end{array}$} \\
\hline & $u_{12}$ & \multicolumn{2}{|c|}{0.50} & \multicolumn{2}{|c|}{1.00} & 0.140 & 0.333 & \\
\hline \multirow{3}{*}{$u_{2} \sim u_{2 j}$} & Index & \multicolumn{2}{|c|}{$u_{21}$} & \multicolumn{2}{|c|}{$u_{22}$} & $l_{2 j}$ & $a_{2 j}$ & \multirow{3}{*}{$\begin{array}{c}\mathrm{CR}=0 \\
\lambda_{\max }=2.000\end{array}$} \\
\hline & $u_{21}$ & \multicolumn{2}{|c|}{1.00} & \multicolumn{2}{|c|}{0.33} & 0.056 & 0.250 & \\
\hline & $u_{22}$ & \multicolumn{2}{|c|}{3.00} & \multicolumn{2}{|c|}{1.00} & 0.169 & 0.750 & \\
\hline \multirow{4}{*}{$u_{3} \sim u_{3 \mathrm{j}}$} & Index & $u_{31}$ & $u_{32}$ & $u_{33}$ & $u_{34}$ & $l_{3 j}$ & $a_{3 j}$ & \multirow{4}{*}{$\begin{array}{l}\mathrm{CR}=0.027 \\
\lambda_{\max }=4.071\end{array}$} \\
\hline & $u_{31}$ & 1.00 & 2.00 & 0.50 & 2.00 & 0.092 & 0.260 & \\
\hline & $u_{33}$ & 2.00 & 3.00 & 1.00 & 3.00 & 0.159 & 0.450 & \\
\hline & $u_{34}$ & 0.50 & 0.50 & 0.33 & 1.00 & 0.043 & 0.120 & \\
\hline
\end{tabular}

Note: $a_{1}-a_{3}$ denote the weight of the production indicator, profit indicator and the quality indicator, respectively. When the consistency ratio index $\mathrm{CR}<0.1$, the consistency test is passed and the indicator evaluation matrix is accepted. 
Table 4 Objective weights of subfactors determined using the entropy method

\begin{tabular}{|c|c|c|c|c|c|c|c|c|}
\hline \multirow{2}{*}{ Treatment } & \multicolumn{2}{|c|}{$u_{1}$} & \multicolumn{2}{|c|}{$u_{2}$} & \multicolumn{4}{|c|}{$u_{3}$} \\
\hline & $u_{11}$ & $u_{12}$ & $u_{21}$ & $u_{22}$ & $u_{31}$ & $u_{32}$ & $u_{33}$ & $u_{34}$ \\
\hline $\mathrm{T} 1$ & 0.095 & 0.101 & 0.131 & 0.129 & 0.122 & 0.116 & 0.102 & 0.111 \\
\hline $\mathrm{T} 2$ & 0.094 & 0.100 & 0.087 & 0.127 & 0.121 & 0.120 & 0.110 & 0.123 \\
\hline $\mathrm{T} 3$ & 0.090 & 0.088 & 0.062 & 0.122 & 0.102 & 0.128 & 0.101 & 0.135 \\
\hline $\mathrm{T} 4$ & 0.113 & 0.102 & 0.156 & 0.115 & 0.122 & 0.105 & 0.127 & 0.110 \\
\hline T5 & 0.117 & 0.119 & 0.109 & 0.119 & 0.129 & 0.102 & 0.139 & 0.103 \\
\hline T6 & 0.118 & 0.116 & 0.082 & 0.120 & 0.121 & 0.111 & 0.129 & 0.115 \\
\hline $\mathrm{T} 7$ & 0.122 & 0.121 & 0.169 & 0.084 & 0.089 & 0.101 & 0.093 & 0.093 \\
\hline $\mathrm{T} 8$ & 0.124 & 0.126 & 0.114 & 0.086 & 0.091 & 0.105 & 0.098 & 0.101 \\
\hline T9 & 0.128 & 0.126 & 0.089 & 0.089 & 0.103 & 0.112 & 0.101 & 0.109 \\
\hline \multirow{2}{*}{ Subfactor weight } & $w_{11}$ & $w_{12}$ & $w_{21}$ & $w_{22}$ & $w_{31}$ & $w_{32}$ & $w_{33}$ & $w_{34}$ \\
\hline & 0.538 & 0.462 & 0.696 & 0.304 & 0.320 & 0.108 & 0.361 & 0.211 \\
\hline
\end{tabular}

Note: $w_{11}$ and $w_{12}$ denote the weight of yield and SFW, $w_{21}$ is the weight of $\mathrm{PFP}_{\mathrm{N}}, w_{22}$ is the weight of IWUE, $w_{31}$ is the weight of VC, $w_{32}$ is the weight of NC, $w_{33}$ is the weight of TSSC, and $w_{34}$ is the weight of FAA.

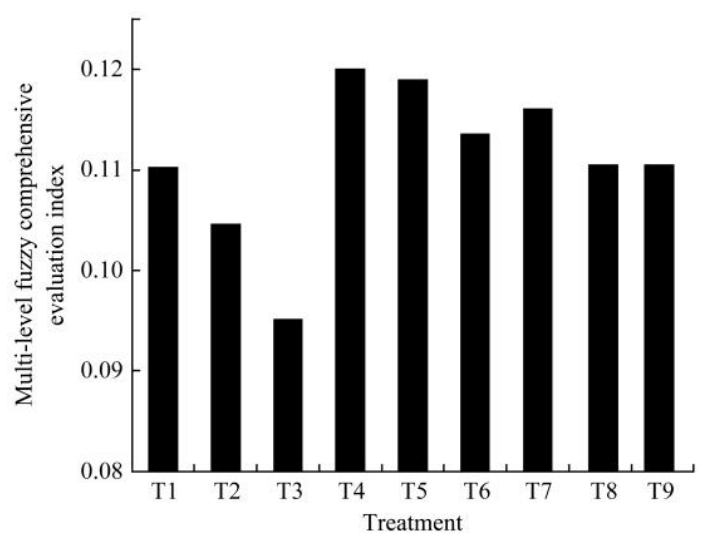

Figure 5 Multi-level comprehensive fuzzy evaluation value of all treatments

\section{Discussion}

A large number of studies have shown that as the amount of irrigation decreases, the yield gradually decreases, which is consistent with the results of the current study. This study also reveals that the decline in yield is related to the decline in SFW. This study is also consistent with several studies, which have drawn similar conclusions in other crops ${ }^{[32]}$. The water deficit, which led to the decrease in yield, may be attributed to the excessive water consumption of plant in order to adapt to the influence of water stress on crop growth ${ }^{[33,34]}$. When the amount of nitrogen is within a certain range, the yield of cucumber rises with an increase in the amount of nitrogen; if the amount of nitrogen exceeds the threshold, the yield is decreased ${ }^{[35]}$. Among all treatments, the highest yield was achieved by T9 (I3N3), and the highest SFW was achieved by T9 (I3N3) (Table 2 and Figure 2). Increased irrigation and nitrogen levels led to decreases in IWUE and $\mathrm{PFP}_{\mathrm{N}}$, negatively affecting the production of crops ${ }^{[36]}$. At the same nitrogen application level, $\mathrm{PFP}_{\mathrm{N}}$ increased with an increase in irrigation (Figure 3). With the irrigation amount remaining the same, the nitrogen amount played limited effect on IWUE.

Excessive irrigation causes a decrease in VC content. Thus, I3 achieved the lowest $\mathrm{VC}$ in three irrigation levels ${ }^{[37]}$. No evidence shows that nitrogen fertilizer affects $\mathrm{VC}$ content in fruits (Table 2). For NC content in fruit, the effect of the nitrogen on it was significantly greater than that of irrigation; however, NC was significantly higher in I1 than in either I2 or I3 (Table 2). The element $\mathrm{N}$ is known to strongly influence the metabolism of matter in the fruit. Thus, with an increase in nitrogen, $\mathrm{NC}$ also increases because excessive supply of $\mathrm{N}$ causes the crop to accelerate its absorption, allowing the crop to store the absorbed nitrate nitrogen, which then accumulates ${ }^{[38]}$. The taste of cucumber largely depends on $\mathrm{TSSC}^{[39]}$. The increase in irrigation was not conducive to the synthesis of TSSC in fruits. If the cucumber was subjected to moderate water stress, the activity of soluble acid invertase and cell wall invertase would be enhanced, which would induce an increase in TSSC content ${ }^{[40]}$. A considerably low irrigation volume also leads to a decrease in TSSC content (I1). With an increase in NC, the TSSC content increased first and then decreased; however, the effect of irrigation on TSSC was more significant (Figure 4). In the present study, the increase in irrigation led to a decrease in FAA. Moreover, the increase in $\mathrm{N}$ was accompanied by an increase in FAA because $\mathrm{N}$ is an essential element for the synthesis of amino acids ${ }^{[41]}$. Among the four qualities of cucumber, the increased VC and TSSC were observed in $\mathrm{I} 2$ (T4, T5, T6). A lower NC positively influenced the quality of cucumber fruit; thus, most of the reduced NC was observed in N1 (T1, T4, T7). The highest FAA was found in N3 (T3, T6, T9) (Table 2).

The AHP and the entropy method were used to determine the weight of each indicator (Tables 3 and 4), and the fuzzy mathematics principle was used to perform multi-level fuzzy comprehensive evaluation of weights. Among the treatments, T4 ranked the first (Figure 5). In previous studies, moderate irrigation and nitrogen yielded the best water-nitrogen coupling effect on cucumber, which was consistent with the results of the current study ${ }^{[42]}$. However, this study comprehensively considered various indicators in the evaluation of cucumber growth, which might have led to the difference in the actual amount of final irrigation and nitrogen between the present study and previous studies. The difference may also be attributed to variations in the environmental condition and management of the greenhouse ${ }^{[43]}$. However, this evaluation method systematically and comprehensively considered different indicators of various aspects of cucumber, rendering the final result credible ${ }^{[44]}$. Therefore, T4 provides an ideal scientific basis for cucumber production in northwest China.

\section{Conclusions}

The yield and SWF of the cucumbers could be significantly improved due to the increment of irrigation and nitrogen 
applications. While the moderate reduction in irrigation and nitrogen can also ensure them to reach a satisfactory level. $\mathrm{PFP}_{\mathrm{N}}$ could be increased when the nitrogen was reduced; and similarly, IWUE could be increased when the irrigation was reduced. In addition to the yield and SWF, the quality of the cucumbers was lowered when irrigation increased; however, a reduction in nitrogen can also secure the quality of the cucumbers to growers.

For different indicators that can characterize the growth of cucumber, their optimal water and fertilizer requirements are not consistent. Therefore, the multi-level fuzzy evaluation method was used to evaluate the eight indicators (from three categories of yield, quality, and profitability for greenhouse cucumbers). The yield index has the greatest impact on the comprehensive growth of cucumber, while the profitability index has the lowest impact. Among all the sub-factors, Yield, $\mathrm{PFP}_{\mathrm{N}}$ and TSSC respectively have the greatest impact on the three factors. Finally, based on the obtained ranks, T4 (Irrigation: $1957.6 \mathrm{~m}^{3} / \mathrm{hm}^{2}, \mathrm{~N}: 60+$ $150 \mathrm{~kg} / \mathrm{hm}^{2}$ ) was concluded as the best strategy of irrigation and nitrogen that suitable for the greenhouse cucumbers in Northwest region of China.

\section{Acknowledgements}

This work was partially supported by the Key Research and Development Program of Shaanxi Province in China (Grant No. 2018TSCXL-NY-05-03), the Xi'an Science and Technology Program in China (Grant No. 2017050NC/NY011(2)) and the Key project for Innovation in Production, Education and Research of Yangling in China (Grant No. 2017CXY-07).

\section{[References]}

[1] Bernacchi C J, VanLoocke A. Terrestrial ecosystems in a changing environment: a dominant role for water. Annu Rev Plant Biol, 2015; 66: 599-622.

[2] Mamun Hossain S A, Wang L X, Liu H S. Improved greenhouse cucumber production under deficit water and fertilization in Northern China. Int J Agric \& Biol Eng, 2018; 11(4): 58-64.

[3] Du T S, Kang S Z, Zhang J H, Li F S. Water use and yield responses of cotton to alternate partial root-zone drip irrigation in the arid area of north-west China. Irrigation Science, 2008; 26(2): 147-159. (in Chinese)

[4] Rahil M H, Qanadillo A. Effects of different irrigation regimes on yield and water use efficiency of cucumber crop. Agricultural Water Management, 2015; 148: 10-15.

[5] China National Agricultural Sustainable Development Plan (2015-2030). http://www.moa.gov.cn/govpublic/FZJHS/201505/t20150527_4620031.ht m. 2015. (in Chinese)

[6] Zhang Z S, Liu M J, Gao H Y, Jin L Q, Li Y T, Li Q M, et al. Water status related root-to-shoot communication regulates the chilling tolerance of shoot in cucumber (Cucumis sativus L.) plants. Scientific Reports, 2015; 5: 10 .

[7] Topcu S, Kirda C, Dasgan Y, Kaman H, Cetin M, Yazici A, et al. Yield response and $\mathrm{N}$-fertiliser recovery of tomato grown under deficit irrigation. European Journal of Agronomy, 2007; 26(1): 64-70.

[8] Ruiz J M, Romero L. Cucumber yield and nitrogen metabolism in response to nitrogen supply. Scientia Horticulturae, 1999; 82(3-4): 309-316.

[9] Mao X S, Liu M Y, Wang X Y, Liu C M, Hou Z M, Shi J Z. Effects of deficit irrigation on yield and water use of greenhouse grown cucumber in the North China Plain. Agricultural Water Management, 2003; 61(3): 219-228.

[10] Benard C, Gautier H, Bourgaud F, Grasselly D, Navez B, Caris-Veyrat C, et al. Effects of low nitrogen supply on tomato (solanum lycopersicum) fruit yield and quality with special emphasis on sugars, acids, ascorbate, carotenoids, and phenolic compounds. Journal of Agricultural and Food Chemistry, 2009; 57(10): 4112-4123.

[11] Gastal F, Lemaire G. N uptake and distribution in crops: an agronomical and ecophysiological perspective. Journal of Experimental Botany, 2002;
53(370): 789-799.

[12] De Pascale S, Maggio A, Orsini F, Barbieri G. Cultivar, soil type, nitrogen source and irrigation regime as quality determinants of organically grown tomatoes. Scientia Horticulturae, 2016; 199: 88-94.

[13] Wang Z Y, Liu Z X, Zhang Z K, Liu X B. Subsurface drip irrigation scheduling for cucumber (Cucumis sativus L.) grown in solar greenhouse based on $20 \mathrm{~cm}$ standard pan evaporation in Northeast China. Scientia Horticulturae, 2009; 123(1): 51-57.

[14] Simsek M, Tonkaz T, Kacira M, Comlekcioglu N, Dogan Z. The effects of dififerent irrigation regimes on cucumber (Cucumbis sativus L.) yield and yield characteristics under open field conditions. Agricultural Water Management, 2005; 73(3): 173-191.

[15] Wang L, Zhang F, Wei X. Effects of different nitrogen fertilization levels on quality and yield of cucumber cultivated in solar greenhouse. Transactions of the CSAE, 2007; 23(12): 225-229. (in Chinese)

[16] Zou Z H, Yun Y, Sun J N. Entropy method for determination of weight of evaluating indicators in fuzzy synthetic evaluation for water quality assessment. Journal of Environmental Sciences, 2006; 18(5): 1020-1023.

[17] Watanabe M, Ohta Y, Sun L C, Motoyama N, Kikuchi J. Profiling contents of water-soluble metabolites and mineral nutrients to evaluate the effects of pesticides and organic and chemical fertilizers on tomato fruit quality. Food Chemistry, 2015; 169: 387-395.

[18] Papageorgiou E I, Aggelopoulou K D, Gemtos T A, Nanos G D. Yield prediction in apples using fuzzy cognitive map learning approach. Computers and Electronics in Agriculture, 2013; 91: 19-29.

[19] Ertek A, Sensoy S, Gedik I, Kucukyumuk C. Irrigation scheduling based on pan evaporation values for cucumber (Cucumis sativus L.) grown under field conditions. Agricultural Water Management, 2006; 81(1-2): $159-172$.

[20] Wang X X, Liu S, Zhang S, Li H, Maimaitiaili B, Feng G, et al. Localized ammonium and phosphorus fertilization can improve cotton lint yield by decreasing rhizosphere soil $\mathrm{pH}$ and salinity. Field Crops Research, 2018; 217: 75-81.

[21] Chen J L, Kang S Z, Du T S, Qiu R J, Guo P, Chen R Q. Quantitative response of greenhouse tomato yield and quality to water deficit at different growth stages. Agricultural Water Management, 2013; 129: $152-162$.

[22] Garcia-Robledo E, Corzo A, Papaspyrou S. A fast and direct spectrophotometric method for the sequential determination of nitrate and nitrite at low concentrations in small volumes. Marine Chemistry, 2014; 162: 30-36.

[23] Leyva A, Quintana A, Sanchez M, Rodriguez E N, Cremata J, Sanchez J C. Rapid and sensitive anthrone-sulfuric acid assay in microplate format to quantify carbohydrate in biopharmaceutical products: Method development and validation. Biologicals, 2008; 36(2): 134-141.

[24] Sun S W, Lin Y C, Weng Y M, Chen M J. Efficiency improvements on ninhydrin method for amino acid quantification. Journal of Food Composition and Analysis, 2006; 19(2-3): 112-117.

[25] Reed B, Chan-Halbrendt C, Tamang B B, Chaudhary N. Analysis of conservation agriculture preferences for researchers, extension agents, and tribal farmers in Nepal using analytic hierarchy process. Agricultural Systems, 2014; 127: 90-96.

[26] Sahoo S, Sil I, Dhar A, Debsarkar A, Das P, Kar A. Future scenarios of land-use suitability modeling for agricultural sustainability in a river basin. Journal of Cleaner Production, 2018; 205: 313-328.

[27] Kundu S, Khare D, Mondal A. Landuse change impact on sub-watersheds prioritization by analytical hierarchy process (AHP). Ecological Informatics, 2017; 42: 100-113.

[28] Zhong F, Hou M, He B, Chen I. Assessment on the coupling effects of drip irrigation and organic fertilization based on entropy weight coefficient model. Peer J, 2017; 5: e3855.

[29] Wang Q S, Yuan X L, Zhang J, Gao Y, Hong J L, Zuo J, et al. Assessment of the sustainable development capacity with the entropy weight coefficient method. Sustainability, 2015; 7(10): 13542-13563.

[30] Hou M M, Lin Z Y, Chen J N, Zhai Y M, Jin Q, Zhong F L. Optimization on theburied depth of subsurface drainage under greenhouse condition based on entropy evaluation method. Entropy, 2018; 20(11): 10.

[31] Liu B J, Chen X H, Lian Y Q, Wu L L. Entropy-based assessment and zoning of rainfall distribution. Journal of Hydrology, 2013; 490: 32-40.

[32] Jensen C R, Battilani A, Plauborg F, Psarras G, Chartzoulakis K, Janowiak $\mathrm{F}$, et al. Deficit irrigation based on drought tolerance and root signalling in potatoes and tomatoes. Agricultural Water Management, 2010; 98(3): 403-413. 
[33] Sensoy S, Ertek A, Gedik I, Kucukyumuk C. Irrigation frequency and amount affect yield and quality of field-grown melon (Cucumis melo L.). Agricultural Water Management, 2007; 88(1-3): 269-274.

[34] Farooq M, Wahid A, Kobayashi N, Fujita D, Basra S M A. Plant drought stress: effects, mechanisms and management. Agronomy for Sustainable Development, 2009; 29(1): 185-212.

[35] Wei Z, Du T, Li X, Fang L, Liu F. Interactive effects of elevated $\mathrm{CO}_{2}$ and $\mathrm{N}$ fertilization on yield and quality of tomato grown under reduced irrigation regimes. Frontiers In Plant Science, 2018; 9: 328.

[36] Zhang H, Xiong Y, Huang G, Xu X, Huang Q. Effects of water stress on processing tomatoes yield, quality and water use efficiency with plastic mulched drip irrigation in sandy soil of the Hetao Irrigation District. Agricultural Water Management, 2017; 179: 205-214.

[37] Dorais M, Papadopoulos A P, Gosselin A. Influence of electric conductivity management on greenhouse tomato yield and fruit quality. Agronomie, 2001; 21(4): 367-383.

[38] Ruiz J M, Romero L. Commercial yield and quality of fruits of cucumber plants cultivated under greenhouse conditions: Response to increases in nitrogen fertilization. Journal of Agricultural and Food Chemistry, 1998; 46(10): 4171-4173.

[39] Jia B, Zheng Q L, Zuo J H, Gao L P, Wang Q, Guan W Q, et al.
Application of postharvest putrescine treatment to maintain the quality and increase the activity of antioxidative enzyme of cucumber. Scientia Horticulturae, 2018; 239: 210-215.

[40] Goldschmidt E E, Huber S C. Regulation of photosynthesis by end-product accumulation in leaves of plants storing starch, sucrose, and hexose sugars. Plant Physiology, 1992; 99(4): 1443-1448.

[41] Gent M P N. Effect of genotype, fertilization, and season on free amino acids in leaves of salad greens grown in high tunnels. Journal of Plant Nutrition, 2005; 28(7): 1103-1116.

[42] Guo R Y, Li X L, Christie P, Chen Q, Zhang F S. Seasonal temperatures have more influence than nitrogen fertilizer rates on cucumber yield and nitrogen uptake in a double cropping system. Environmental Pollution, 2008; 151(3): 443-451.

[43] Haramoto E, Belfry K D, Trueman C, Vyn R J, Loewen S A, Van Eerd L L. Winter cover crops on processing tomato yield, quality, pest pressure, nitrogen availability, and profit margins. Plos One, 2017; 12(7): e0180500.

[44] Maddahi Z, Jalalian A, Zarkesh M M K, Honarjo N. Land suitability analysis for rice cultivation using a gis-based fuzzy multi-criteria decision making approach: Central part of Amol District, Iran. Soil and Water Research, 2017; 12(1): 29-38. 